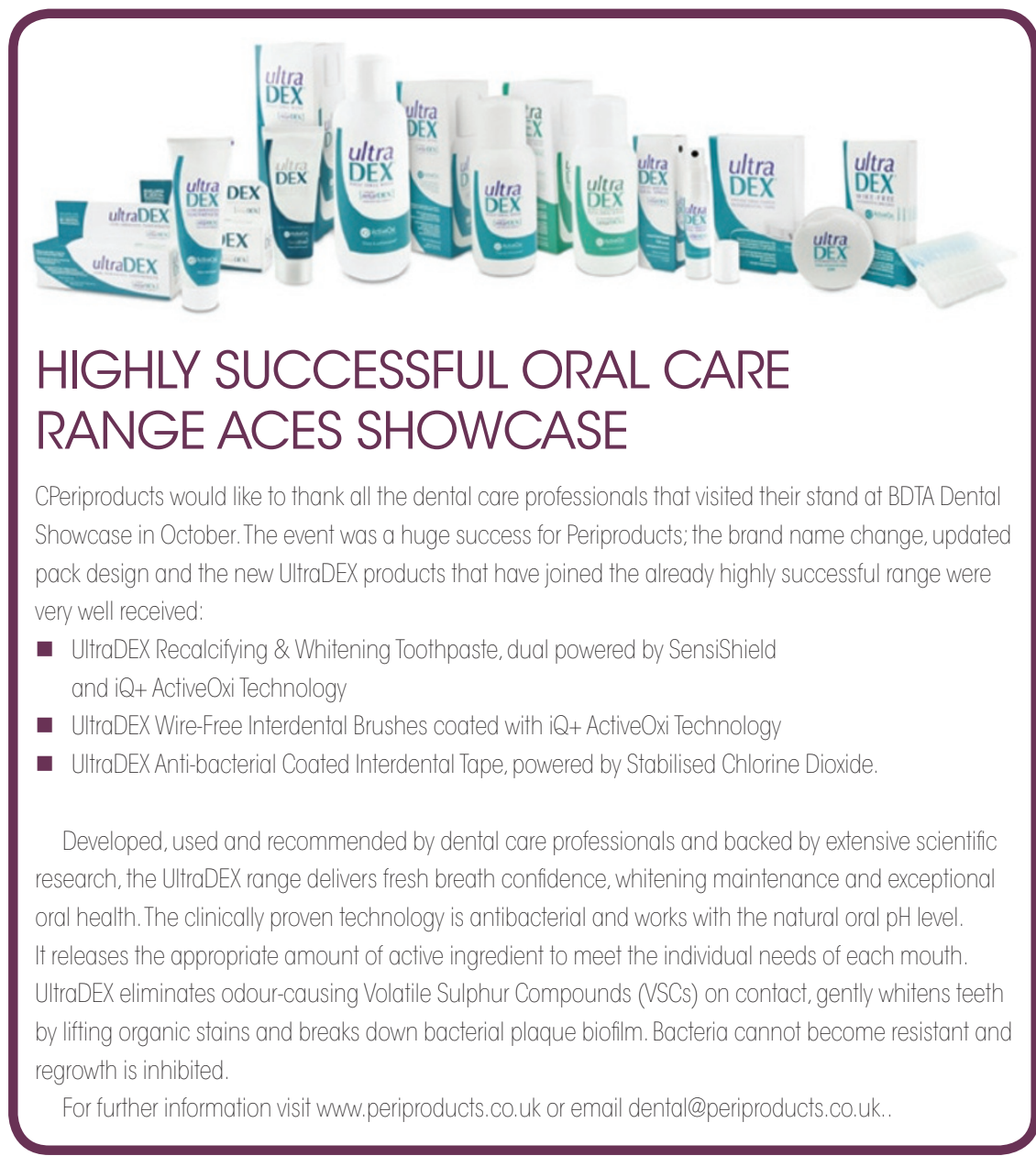

\section{FORGE A FANTASTIC DENTAL CAREER}

Smiles Dental and JHA are proud to offer all dental professionals a diverse and rewarding career pathway. They provide financial support and guidance to professionals in all areas such as CPD training, management and indemnity cover, and are committed to ensuring all members of their team meet their full potential. Fantastic internal opportunities are available across 70 practices in the UK, each promoting a friendly and dynamic team culture that strives for clinical excellence. Whether you are dental nurse or front of house professional looking for full or part time work, JHA can help you develop your skills and advance in your career with their top-quality facilities and up-to-date technologies. Join the outstanding JHA team today! For information about JHA call 02920772955 or visit www.jameshull.co.uk.

\section{WATER WAY TO FLOSS THE TEETH}

Water Pik celebrated the launch of two new products at BDTA Dental Showcase: Waterpik Complete Care and the Sensonic Professional Plus sonic toothbrush

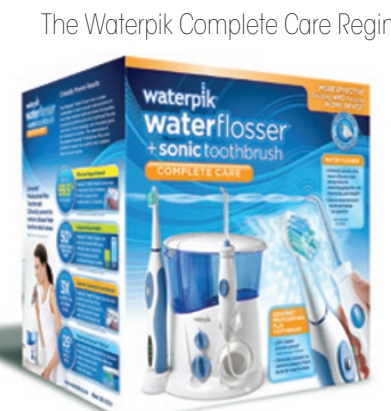
comines proven Water Flosser and Sonic Toothbrush technologies for easy and more effective brushing and flossing in one convenient device that saves space and power outlets. The Sensonic Professional Plus sonic toothbrush removes significantly more plaque than other sonic toothbrushes with its 25\% faster filament speed. Its features include an ergonomic handle design with no-slip grip, extra soft, end-rounded filaments, a two-minute timer, 30-second quadrant pacer and three unique brush heads. Waterpik products are widely available in Boots stores, Argos and selected Lloyds Pharmacies. mww.waterpik.co.uk

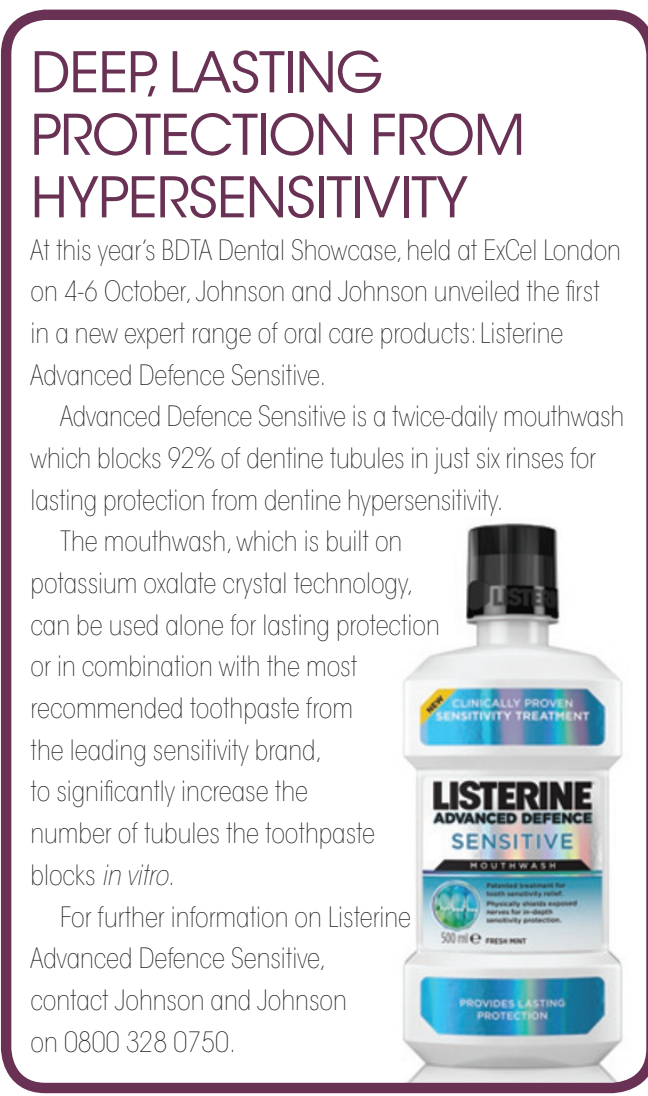

\section{BECOME A TREATMENT COORDINATOR}

Laura Horton Consulting now offers a BTEC in treatment

coordination, a 9-12 month programme covering all

aspects of treatment coordination, with four modules for

students to work through.

Laura Horton Consulting have also launched a

treatment coordinator video elearning programme. For

more information visit www. tco-online.com

www.laurahortonconsulting.co.uk

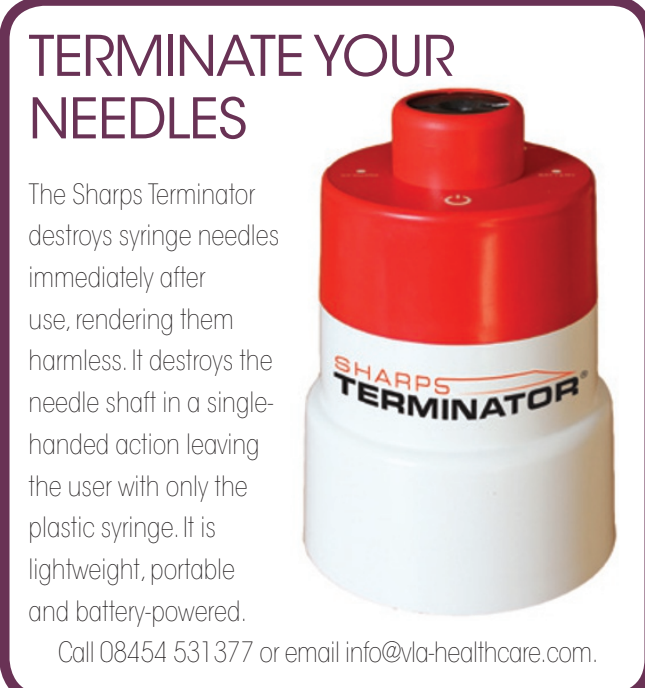

If you would like to promote your products or services direct to the dental industry through VITAL UPDATE telephone Andy or Lyle on 02078434729. 